\title{
Optimization of tungsten castellated structures for the ITER divertor
}

\author{
A.Litnovsky $^{1 *}$, M. Hellwig ${ }^{1}$, D.Matveev ${ }^{1,2}$, M. Komm³ ${ }^{3}$ M. van den Berg ${ }^{4}$, G. De Temmerman ${ }^{4}$,

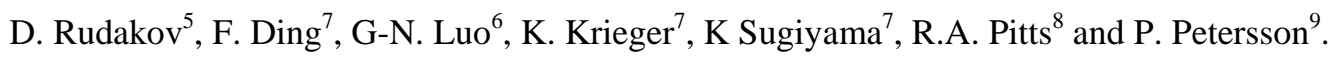

${ }^{1}$ Institute of Energy and Climate Research - Plasma Physics, , Forschungszentrum Jülich, Trilateral Euregio Cluster, Association EURATOM- FZ Jülich, D 52425 Jülich, Germany;

${ }^{2}$ Department of Applied Physics, Ghent University, Plateaustraat 22, B-9000 Ghent, Belgium;

${ }^{3}$ Institute of Plasma Physics AS CR, v.v.i., Za Slovankou 3, 18200 Prague 8, Czech Republic;

${ }^{4}$ FOM Institute DIFFER - Dutch Institute for Fundamental Energy Research, Postbus 1207, 3430BE, Nieuwegein, The Netherlands;

${ }^{5}$ University of California, San Diego, La Jolla, California 92093-0417, USA;

${ }^{6}$ Institute of Plasma Physics, Chinese Academy of Sciences, Hefei, China;

${ }^{7}$ Max-Planck-Institut für Plasmaphysik, EURATOM Association, D-85748 Garching, Germany;

${ }^{8}$ ITER Organization, Route de Vinon sur Verdon, CS 90046 - 13067, St. Paul Lez Durance Cedex, France;

${ }^{9}$ Royal Institute of Technology, SE-100, 44 Stockholm, Sweden.

PACS: 52.55.Fa; 52.40.Hf; 52.25.Vy

PSI 21 Keywords: Deuterium inventory, Erosion \& Deposition, High-Z material, Tungsten, TEXTOR

Corresponding and presenting author: Dr. Andrey Litnovsky

Corresponding and presenting author address: Institut für Energieforschung - Plasmaphysik, Forschungszentrum Jülich, D-52425 Jülich, Germany

Corresponding and presenting author E-mail: a.litnovsky@fz-juelich.de 


\section{Abstract}

In ITER, the plasma-facing components (PFCs) of the first wall and the divertor armor will be castellated to improve their thermo-mechanical stability and to limit forces due to induced currents. The fuel accumulation in the gaps may significantly contribute to the in-vessel fuel inventory. Castellation shaping may be the most straightforward way to minimize the fuel inventory and to alleviate the thermal loads onto castellations.

A new castellation shape was proposed and comparative modeling of conventional (rectangular) and shaped castellation was performed for ITER conditions. Shaped castellation was predicted to be capable to operate under stationary heat load of $20 \mathrm{MW} / \mathrm{m}^{2}$. An 11-fold decrease of beryllium (Be) content in the gaps of the shaped cells alone with a 7-fold decrease of carbon content was predicted. In order to validate the predictive capabilities of modeling tools used for ITER conditions, the dedicated modeling with the same codes was made for existing tokamaks and benchmarked with the results of multi-machine experiments. For the castellations exposed in TEXTOR and DIII-D, the carbon amount in the gaps of shaped cells was 1.9-2.3 times smaller than that of rectangular ones. Modeling for TEXTOR conditions yielded to 1.5-fold decrease of carbon content in the gaps of shaped castellation outlining fair agreement with the experiment. At the same time, a number of processes, like enhanced erosion of molten layer yet need to be implemented in the codes in order to increase the accuracy of predictions for ITER.

\section{Introduction and motivation}

In future fusion reactors like ITER, the armor of the divertor and the entire first wall will be castellated to improve their thermo-mechanical durability and to decrease the load induced by the induced currents. The castellation will be made by splitting the plasma-facing components into the compact-sized monoblocks thus introducing the gaps between them. Besides the positive effects like reduced risk of cracking, the castellation will lead to the increased probability of melting of the castellated PFCs due to local power loads on leading edges of the gaps. Apart from that, tritium can become trapped in the gaps of the castellation contributing to the undesirable fusion fuel inventory. In order to alleviate the mentioned adverse effects, the shaping of the castellated components was 
proposed. The conventional and new geometry of the tungsten castellated PFCs are provided in figure 1.

The new geometry features a chamfer on the side of the castellation facing the plasma flow. This is made to avoid the possible leading edges. The rear side of the castellation has a small rounding of 0.5 $\mathrm{mm}$ in radius in order to maximize the plasma-wetted area.

\section{Modeling}

\section{Thermal response to plasma load}

The thermal response of the castellation was assessed using the commercial ANSYS finite element package. The castellation was exposed under the angle of $3^{\circ}$ to the radially uniform plasma load of 10 $\mathrm{MW} / \mathrm{m}^{2}$ and $20 \mathrm{MW} / \mathrm{m}^{2}$ onto plasma-wetted surfaces as it is shown on figure 2. Both aligned and misaligned castellations were modeled. The maximum tolerable cumulative vertical misalignment of $0.3 \mathrm{~mm}$ was assumed in the simulations. The results of the simulations for the $20 \mathrm{MW} / \mathrm{m}^{2}$ of stationary heat load are presented on figure 2. The shaped castellation reaches the temperature of $2700^{\circ} \mathrm{C}$, more than $700^{\circ} \mathrm{C}$ below the melting point of tungsten. At the same time, the conventional rectangular castellation is heated up to $\sim 3300^{\circ} \mathrm{C}$ (fig 2c) almost reaching the melting point of tungsten $\mathrm{T}_{\mathrm{Wm}}=3422^{\circ} \mathrm{C}$ thus bringing the castellated structure to an unacceptable risk of melting.

\section{Plasma ion flux onto castellation}

The ion loads were simulated using the SPICE2 particle-in-cell plasma code described in [1]. The initial plasma parameters relevant to those expected in ITER at the outer baffle: $\mathrm{T}_{\mathrm{e}}=\mathrm{T}_{\mathrm{i}}=12 \mathrm{eV}$, $\mathrm{N}_{\mathrm{e}}=2 * 10^{13} \mathrm{~cm}^{-3}$ were assumed for SPICE2. The distribution of the particle flux along the surface of the castellation is shown on figure 3. In case of rectangular castellation, one can see the characteristic peak of the ion flux penetrating into the gap on its part facing plasma directly. In case of shaped castellation, this part is in the shadow due to chamfer and the ion flux is not peaked there. The absence of the ion source inside the gap is responsible for the absence of ion penetration in the gap which is a remarkable result.

Deposition in the gaps 
The impurity deposition was evaluated with the Monte-Carlo package 3D-GAPS [2]. Due to limitations of computational capacity, for the modeling either fixed plasma parameters mentioned above: $\mathrm{T}_{\mathrm{e}}=\mathrm{T}_{\mathrm{i}}=12 \mathrm{eV}, \mathrm{N}_{\mathrm{e}}=2 * 10^{13} \mathrm{~cm}^{-3}$ or input from the SPICE2 code was used. The distribution of Be deposition onto the castellation and inside the gaps is provided on the figure 4. Input from SPICE2 was used to determine the plasma parameters in the vicinity of the gap. The initial Be content in plasma was assumed to be $5 \%$. Much lower deposition in the shaped gap as compared with the conventional one can be expected according to modeling. A 11-fold reduction of the beryllium deposition inside the gap was predicted. Similar calculations performed for carbon yielded a 7-fold suppression of carbon deposition in the gaps of the shaped cells.

The results of the predictive modeling of thermal response, the ion load onto castellation along with impurity migration in the conventional and new shape tungsten blocks demonstrate sound advantages of the new shape. It was therefore decided to study these aspects of the new castellation shape experimentally, providing an opportunity for code benchmarking and for experimental validation of the new shaping.

\section{Experimental studies}

\section{Material migration in the gaps}

Material transport in the gaps of shaped and conventional castellation was investigated using the tungsten castellation reproducing the part of the full-scale castellation, as shown with the dashed fragment in the figure 1 . The smaller castellation used in the studies was called "reduced-geometry" (RG) castellation. The dedicated modeling was performed to investigate the similarity of expected ion loads for the full-scale and reduced-geometry castellation using the plasma conditions expected in ITER and mentioned above. The obtained modeling predictions on ion load are similar for both geometries allowing us to use the reduced geometry for the subsequent studies. An example of the comparative modeling for FS and RG castellations is shown in figure 5 for rectangular blocks. The dedicated modeling was performed for plasma conditions in existing tokamaks to estimate the expected effect on castellation. The modeled values of suppression of carbon deposition in the gaps of shaped cells are sensibly less than that predicted by the modeling for ITER conditions. For instance, for typical conditions in the SOL plasma in TEXTOR: $\mathrm{T}_{\mathrm{e}}=\mathrm{T}_{\mathrm{i}}=40 \mathrm{eV}, \mathrm{N}_{\mathrm{e}}=5 * 10^{12} \mathrm{~cm}^{-3}$, the expected 
suppression of carbon deposition to the castellation exposed at $3^{\circ}$ to the magnetic field is 1.5 . The possible reasons will be described later in the paper.

The "ITER-grade” RG castellation was manufactured according to the specifications [3]. The manufactured castellation sets comprised both shaped and rectangular castellation blocks allowing the direct comparison of the results. Exposures of castellation were performed in TEXTOR and DIII-D tokamaks. The special holder containing the three RG castellation sets inclined at $20^{\circ}, 10^{\circ}$ and $3^{\circ}$ to the magnetic field were exposed in TEXTOR whereas in DIII-D experiment only the castellation inclined at $3^{\circ}$ to magnetic field was exposed. We will focus therefore our analyses on the blocks exposed at $3^{\circ}$. In TEXTOR, the castellation was introduced from the top of the machine using the limiter lock 3 material transport system [4]. The castellation was exposed to the plasma at the radial distance of $47,2 \mathrm{~cm}, 2,2 \mathrm{~cm}$ behind the last closed magnetic surface. In total, 22 identical neutralbeam heated discharges were conducted with the total plasma duration of 130 seconds. Electron temperature and density were: $\mathrm{T}_{\mathrm{e}} \sim 40 \mathrm{eV}$ and $\mathrm{N}_{\mathrm{e}} \sim 4 * 10^{12} \mathrm{~cm}^{-3}$, as inferred from the data of heliumbeam diagnostics.

Another set of the castellation was exposed in the DIII-D tokamak in the outer strike point position in the outer divertor using DiMES transport system [5]. The RG castellation was mounted in the DiMES head in the similar manner as described in [6]. In total 29 discharges were made with the total plasma duration of $\sim 100$ seconds. The castellation was exposed to colder and less dense plasmas: $\mathrm{N}_{\mathrm{e}} \sim 1.5 * 10^{12}$ $\mathrm{cm}^{-3}, \mathrm{~T}_{\mathrm{e}} \sim 15 \mathrm{eV}$ than that during exposure in TEXTOR. Data from divertor Langmuir probes [7] was used to evaluate the plasma parameters in DIII-D.

After exposure, the castellation sets were dismounted and analyzed using ion- and electron-beam surface diagnostics to evaluate the deposition patterns. Carbon deposition profiles in both experiments are similar despite different exposure conditions. Carbon distributions along the gap are very peaked in the uppermost plasma-closest parts in a full analogy with previous investigations of castellated structures in TEXTOR [8-10]. As an example, results of electron-probe microanalysis (EPMA) measurements of carbon and nuclear reaction analyses (NRA) of deuterium co-deposited onto castellation exposed in TEXTOR and in DIII-D are provided in figure 6 as the distribution of areal atomic concentration along the length of the gap as shown on the scheme in this figure. Total carbon 
deposition was obtained by integrating the carbon amount along the line scan in the depth of the gap performed with EPMA and by multiplying this amount with the width of the gap. The background levels of impurities were measured on identical virgin samples. These background values were then subtracted from measured profiles. Both experiments show the advantages of castellation shaping. Experimentally found reduction of carbon deposition in the gaps of the shaped cells was estimated to be $\mathrm{N}_{\text {Ctotal.rectangular }} / \mathrm{N}_{\text {Ctotalshaped }}=1.9-2.3$.

\section{Analyses and code benchmarking}

Measured deposition patterns were simulated using the 3D-GAPS code. As the source plasma parameters, measured values of electron density and temperature were used. The Monte-Carlo simulation code includes the following processes:

- Reflection

- Re-erosion and re-deposition

- Physical sputtering

- Chemical erosion

- Particle Implantation

As for detailed reconstruction of impurity deposition pattern, modeling results for rectangular geometry match well experimental data. The results are a bit less encouraging for of shaped castellation. The normalized experimental distributions of areal atomic carbon concentration along the gap are plotted in figure 7 alone with simulated profiles of carbon deposition. The modeled and the experimental profiles do not match each other, even qualitatively. The largest deviation is at the plasma-closest areas of gaps, where the amount of detected and modeled impurities is the largest. The observed discrepancy in deposition in the gaps of shaped cells may arise from different factors. One such a factor is the surface roughness which will significantly influence the reflection of particles. The roughness of the castellation surface may be responsible for more peaked measured profiles of impurities than those modeled. The roughness of exposed tungsten samples was measured using atomic force microscope and appeared to be quite high $\mathrm{R}_{\mathrm{RMS}} \sim 1$ um. The modeled moderate 
suppression of deposition may be due to the electrostatic potential inside the gap and is responsible for plasma penetration into the gap and defines the resulting plasma parameters there. Additional uncertainty may arise from the carbon re-deposition and re-erosion due to neutral atoms which are not treated in the codes. However, given relatively high electron temperature during experiments, this factor is unlikely to play the major role. It is also confirmed by relatively good agreement between experiment and modeling. At last, the observed more moderate effect in the suppression of carbon deposition as predicted for ITER and measured in TEXTOR and DIII-D may be due to large difference in initial plasma parameters at the castellation. As described in [1] in ITER conditions the plasma penetration is largely governed by the local geometry of the castellation, whereas for e.g. TEXTOR the penetration is mostly dependent on the formation of electrostatic potential in the gap, which outline the importance in more precise assessment of the latter. Dedicated experimental studies of the influence of particle reflection on impurity deposition alone with the respective update of the code are under preparation.

\section{Summary and outlook}

A new shape of tungsten castellation was proposed for ITER new divertor. The shape comprises the chamfer to avoid the hot leading edges and the rounding to increase the plasma-wetted area. Series of predictive modeling efforts for ITER conditions pointed to expected sound advantages of the new shape: the misplaced castellation will not melt even being exposed to $20 \mathrm{MW} / \mathrm{m}^{2}$ steady-state plasma. The ion flux onto castellation will be suppressed. The 11-fold reduction of beryllium in the gaps of shaped castellation is expected.

In order to validate the predictive capability of codes, modeling was made for the conditions in existing tokamaks. Subsequently, series of experiments were made in TEXTOR and DIII-D tokamaks using identical tungsten castellation sets. Profiles of impurity deposition in the gaps are strongly peaked having the maximum at the uppermost plasma-closest areas, as expected. The measured reduction of carbon deposit in the shaped gaps was 1.9 - 2.3 compared with modeled 1.5 demonstrate a fair agreement between experiment and modeling. Detailed reconstruction of measured profiles of carbon deposition in gaps worked well for rectangular geometry of monoblocks. At the same time, no 
qualitative agreement of measured and modeled carbon distributions in the gaps of shaped cells is reached yet evidencing missing or underestimated factors in the codes and calling for their further update and validation. Among those missing factors is the surface roughness affecting the reflection

of particle in the gaps and the detailed distribution of electrostatic potential responsible for plasma penetration inside the gap. In ITER conditions the other mechanisms of tungsten surface erosion evolving e.q. tungsten cracking, melting and subsequent erosion of molten layer may play an important role and therefore need to be assessed too.

Further investigations of castellation shaping are ongoing. These efforts include the code tuning and upgrade, tests of castellation in EAST, KSTAR and ASDEX Upgrade tokamaks along with reference experiments with the ion-beam facility at FZJ to study the role of surface roughness on particle reflection experimentally. The thermal load tests have been performed recently in the linear plasma simulator MAGNUM PSI using the full-scale castellation. Analyses are ongoing and will be reported in the dedicated publication.

\section{References}

[1] M Komm, R Dejarnac, J P Gunn et al., Plasma Phys. Control. Fusion 53 (2011) 115004;

[2] D. Matveev, A. Kirschner, A. Litnovsky et al., Plasma Phys. Control. Fusion 52 (2010) 075007;

[3] ITER Tungsten Bar Procurement Specifications, ITER Document: ITER_D_2X38PN;

[4] B. Schweer, S. Brezinsek, H.G. Esser et al, Fus. Science and Technology vol. 47 No.2 (2005) 138;

[5] C. P. C. Wong, D. G. Whyte, R. J. Bastasz et al, J. Nucl. Mater. 433 (1998) 258;

[6] D. L. Rudakov, C. P. C. Wong, A. Litnovsky et al, Phys. Scr. T138 (2009) 014007;

[7] J. G. Watkins, D. Taussig, R. L. Boivin, M. A. Mahdavi and R. E. Nygren

Rev. Sci. Instrum. 79 , 10F125 (2008);

[8] A. Litnovsky, P. Wienhold, V. Philipps et al., J. Nucl. Mater, 390-391 (2009) 556;

[9] A. Litnovsky, V. Philipps, P. Wienhold et al., J. Nucl. Mater, 386-388 (2009) 809;

[10] A. Litnovsky, V. Philipps, P. Wienhold et al Journal of Nuclear Materials 415 (2011) S289. 


\section{Figure captions:}

Figure 1. Conventional and shaped tungsten castellation.

Figure 2. Thermal response to the stationary radially uniform thermal load of $20 \mathrm{MW} / \mathrm{m}^{2}$ of:

a) conventional aligned castellation, b) shaped aligned castellation, c) conventional misaligned castellation and d) shaped misaligned castellation.

Figure 3. Ion load onto a) rectangular and b) shaped misaligned castellation.

Figure 4. Beryllium deposition on a) aligned conventional, b) aligned shaped, c) misaligned conventional, d) misaligned shaped castellation. The directions along the gap are shown in the scheme.

Figure 5. Comparison of the ion load onto the rectangular castellation for the full-scale (FS) and reduced geometry (RG) monoblock. The directions of axes is the same as in figure 3.

Figure 6. Areal distribution of carbon and deuterium along the poloidal gap of the rectangular castellation exposed a) in TEXTOR and b) in DIII-D.

Figure 7. Carbon atom distribution as measured and modeled for the gaps of shaped cells exposed in TEXTOR: a) for plasma-shadowed part of the gap and b) for plasma-open part. The scheme of plasma exposure is shown in (b). 


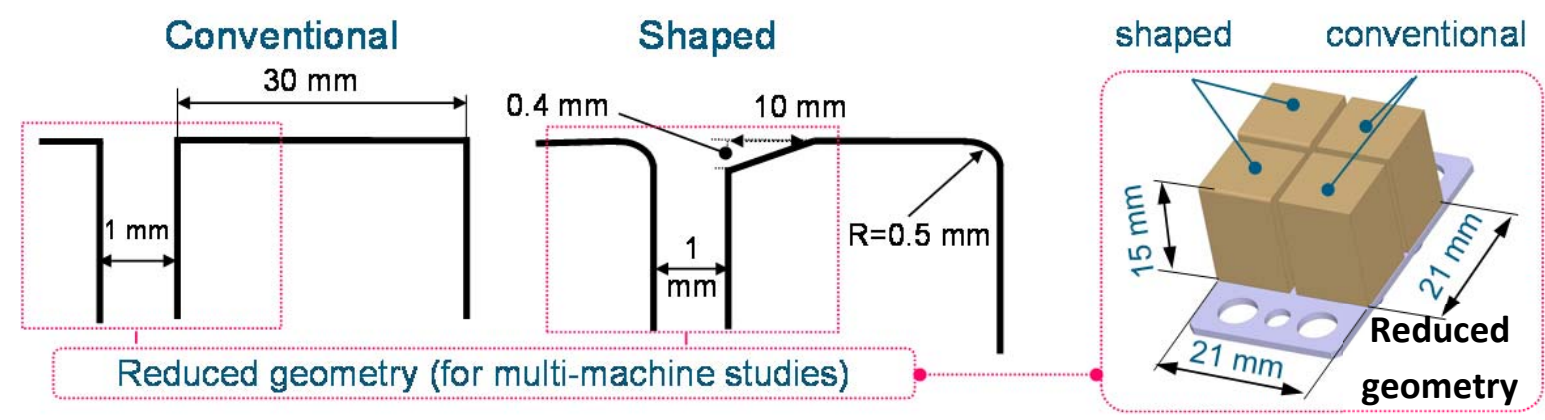

Figure 1. Conventional and shaped tungsten castellation 


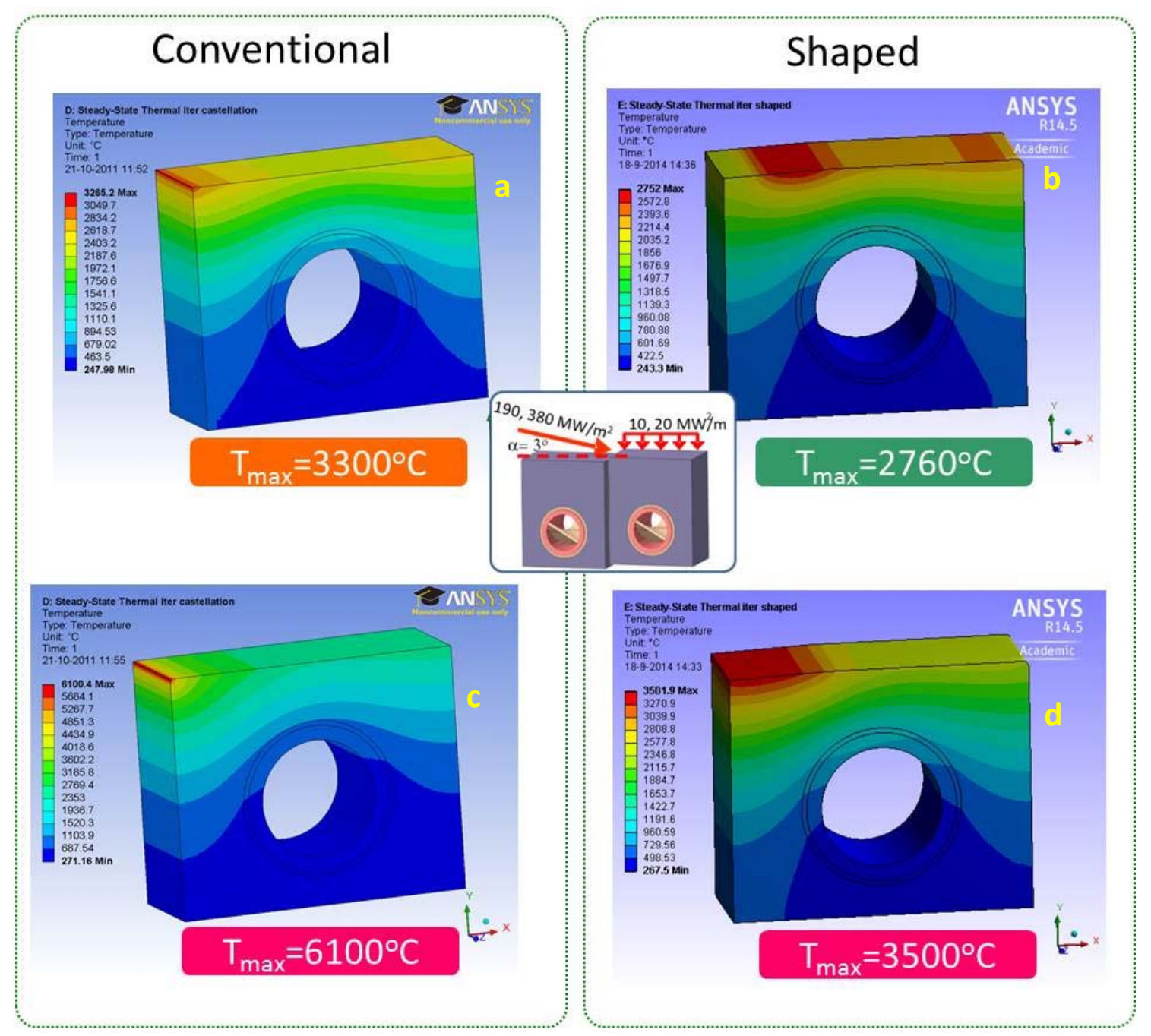

Figure 2. Thermal response to the stationary radially uniform thermal load of $20 \mathrm{MW} / \mathrm{m}^{2}$ of: a) conventional aligned castellation, b) shaped aligned castellation, c) conventional misaligned castellation and d) shaped misaligned castellation. 

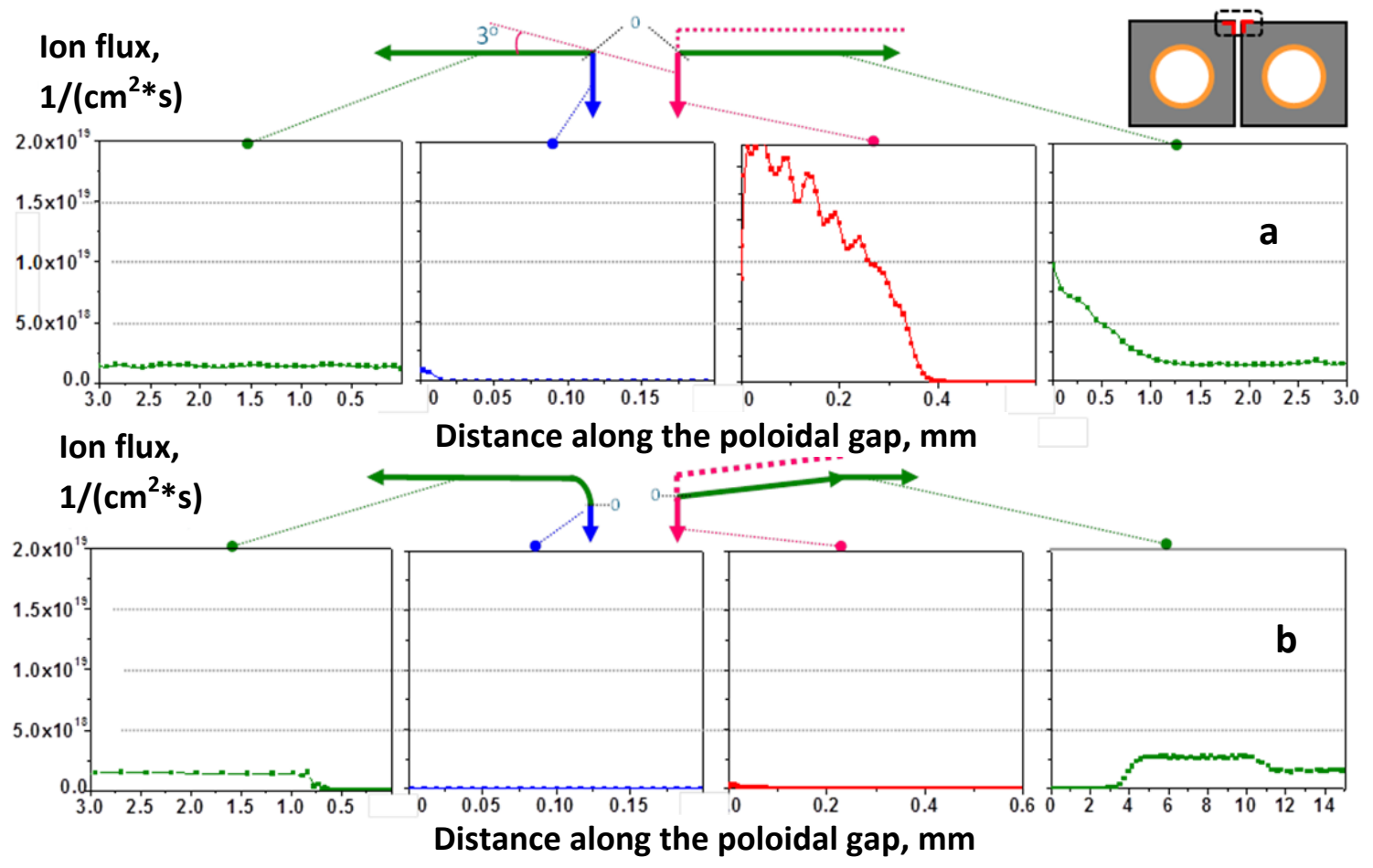

Figure 3. Ion load onto a) rectangular and b) shaped misaligned castellation. Arrows show the top surfaces of the castellation along with uppermost part of the gap. The simulated area is shown in the caption. 

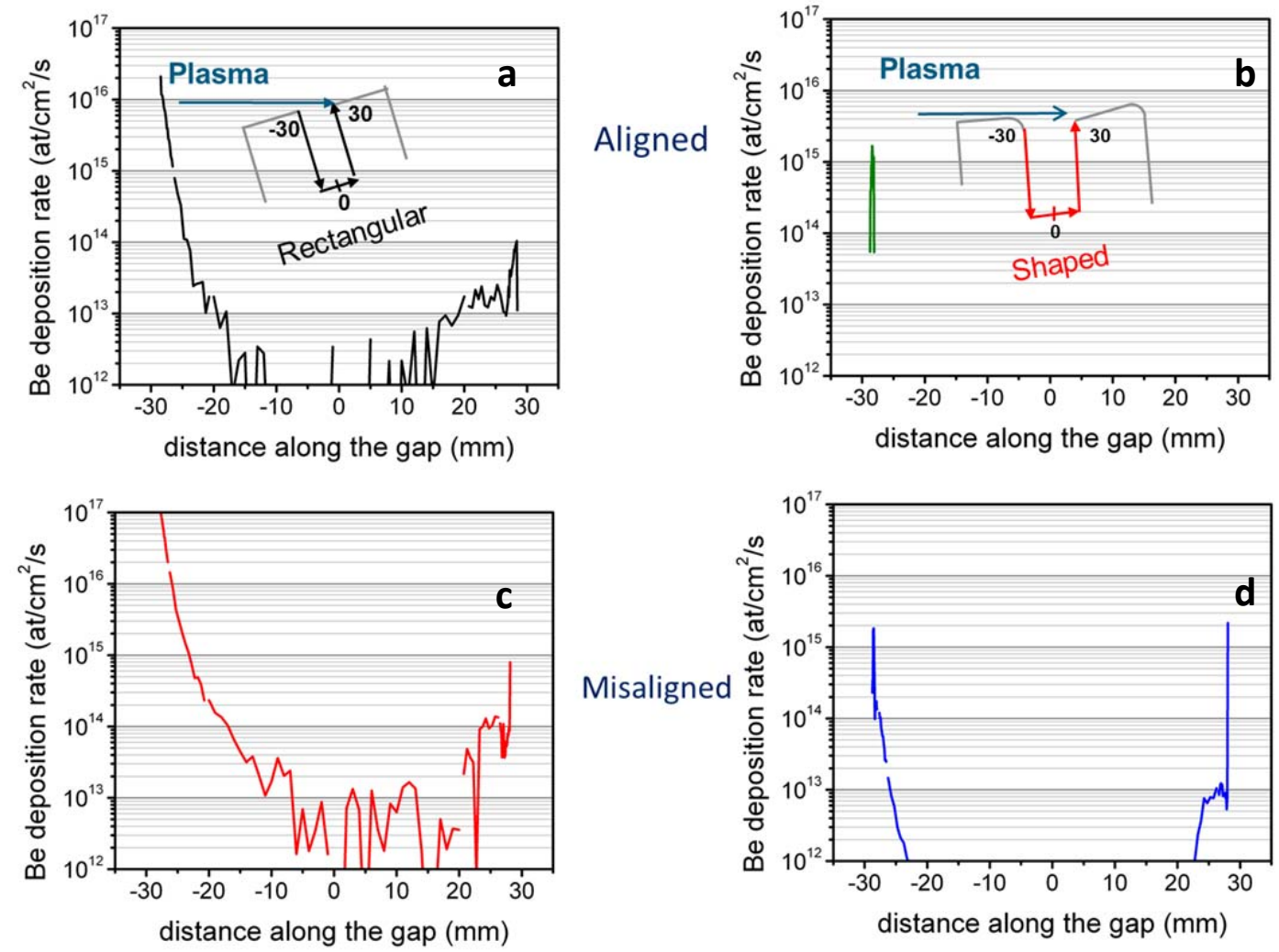

Figure 4. Beryllium deposition on a) aligned conventional, b) aligned shaped, c) misaligned conventional, d) misaligned shaped castellation. The directions along the gap are shown in the scheme. 


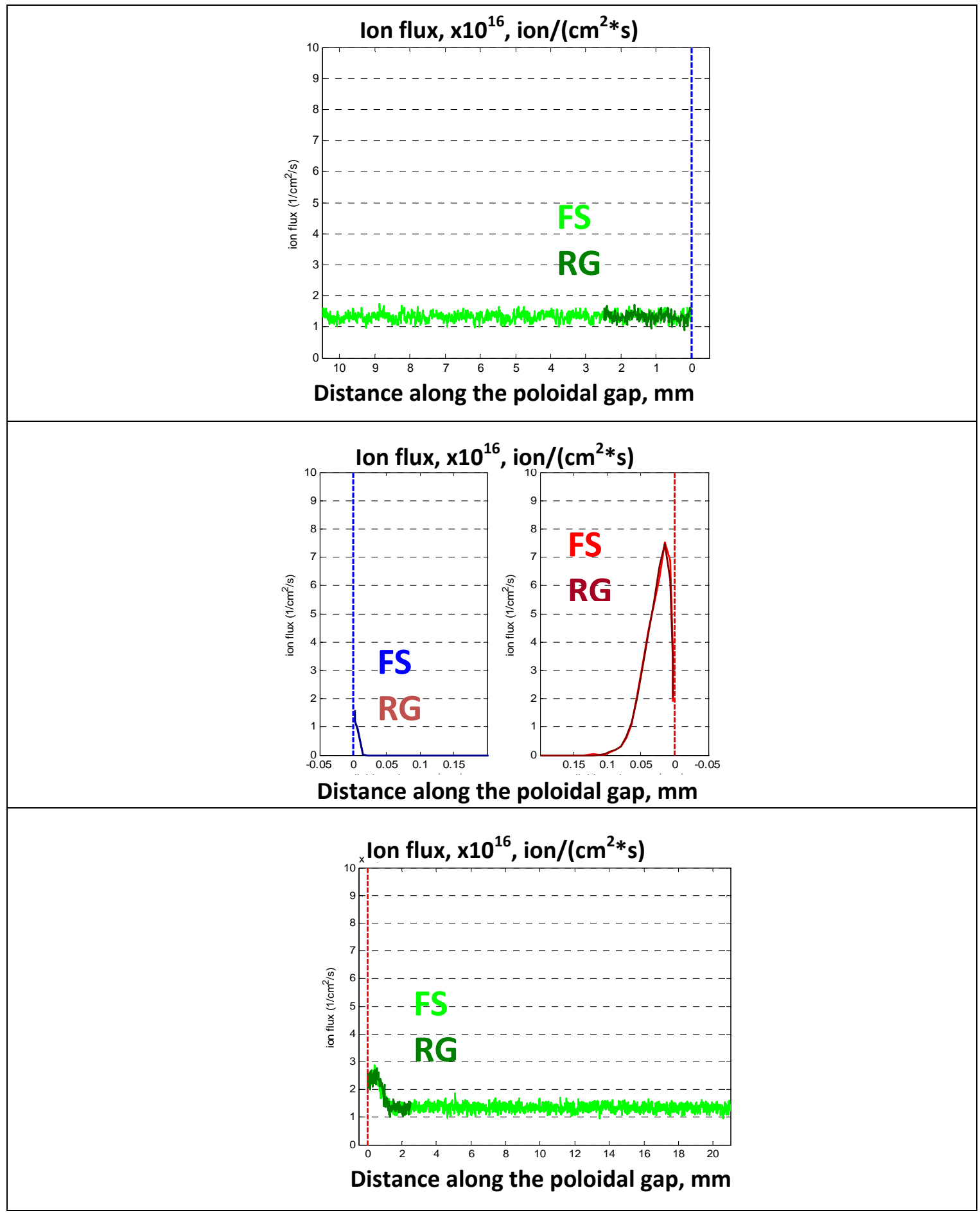

Figure 5. Comparison of the ion load onto the rectangular castellation for the full-scale (FS) and reduced geometry (RG) monoblock. The directions of axes is the same as in figure 3. 

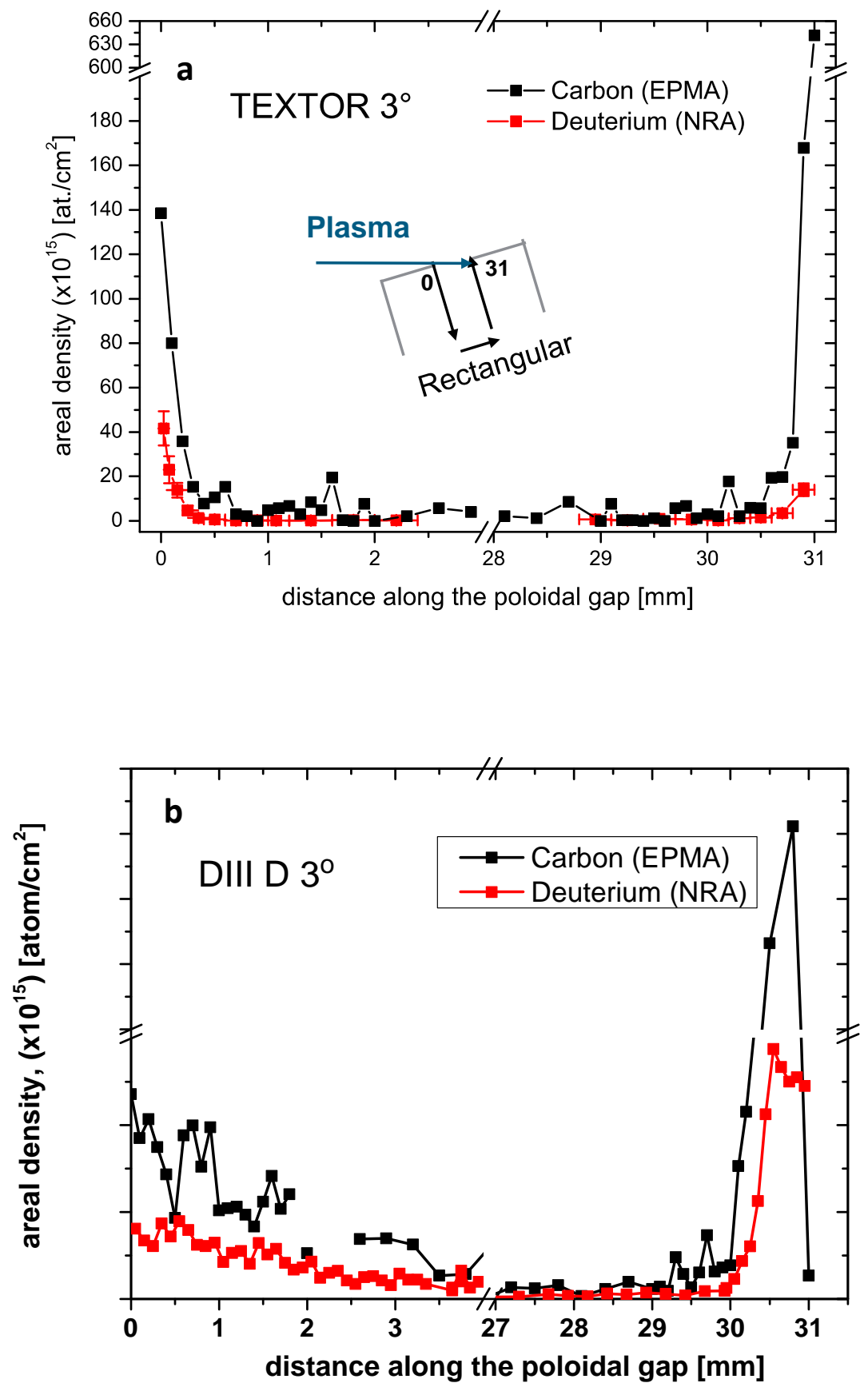

Figure 6. Areal distribution of carbon and deuterium along the poloidal gap of the rectangular castellation exposed a) in TEXTOR and b) in DIII-D. 

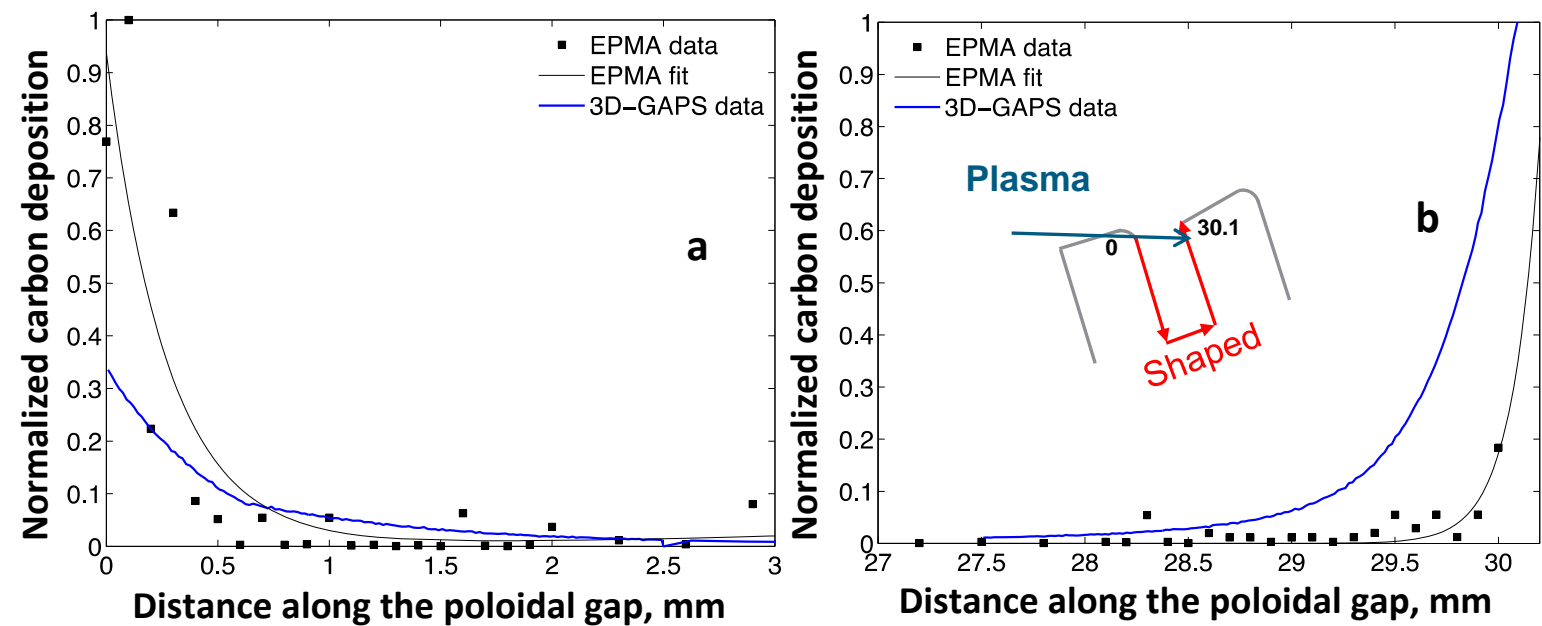

Figure 7. Carbon atom distribution as measured and modeled for the gaps of shaped cells exposed in TEXTOR: a) for plasma-shadowed part of the gap and b) for plasma-open part. The scheme of plasma exposure is shown in (b). 